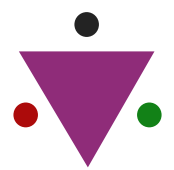

IJCRR

Section: Healthcare

Sci. Journal Impact

Factor: $6.1(2018)$

ICV: 90.90 (2018)

(c) (7) (8)

Copyright@IJCRR

\title{
Development of a Rapid Chemometric Reverse Phase HPLC Method for the Simultaneous Estimation of Paracetamol and Ibuprofen in Bulk and Tablet Formulation
}

\author{
Sangameshwar B. Kanthale ${ }^{1}$, Sanjay S. Thonte², Sanjay S. Pekamwar ${ }^{1}$, \\ Debarshi Kar Mahapatra ${ }^{3}$
}

'School of Pharmacy, Swami Ramanand Teertha Marathwada University, Nanded 431606, Maharashtra, India; ${ }^{2}$ Channabasweshwar Pharmacy College, Latur 431512, Maharashtra, India; ${ }^{3 D}$ epartment of Pharmaceutical Chemistry, Dadasaheb Balpande College of Pharmacy, Nagpur 440037, Maharashtra, lndia.

\section{ABSTRACT}

Introduction: Developing and optimizing isocratic HPLC methods is a difficult procedure that requires simultaneous determination of several factors.

Objective: To develop a simple, accurate, rapid, and precise chemometric-assisted RP-HPLC method for the simultaneous estimation of Paracetamol (PARA) and Ibuprofen (IBU) in bulk and in pharmaceutical formulation.

Methods: The method involves the design of experiment (DOE) approach for the optimization of the mobile phase by keeping in concern about the dependent variables (flow rate, methanol, and $\mathrm{pH}$ ) and their consequence was perceived over the retention time (Rt) and resolution of drugs.

Results: Based on the trial runs, the optimized condition generated by the software was used for the separation of PARA and IBU on Thermo C18 Column (150 mm $\times 4.6 \mathrm{~mm}$ i.d., $5 \mu \mathrm{m}$ ). The chromatographic separation was achieved by using the optimized mobile phase consisting of methanol and sodium dihydrogen phosphate buffer (88.3: $11.7 \% \mathrm{v} / \mathrm{v})$, adjusted to $\mathrm{pH} 2.5$, delivered at a flow rate of $1.2 \mathrm{~mL} / \mathrm{min}$ and the detection was carried out at $222 \mathrm{~nm}$. The retention time (Rt) was found to be 2.241 minutes for PARA and 3.535 minutes for IBU. The developed method was validated as per ICH guidelines. The calibration curves of PARA and IBU were found to be linear in the range of $6.5-39 \mu \mathrm{g} / \mathrm{mL}$ and $8-48 \mu \mathrm{g} / \mathrm{mL}$, respectively. The recoveries for the two compounds were close to $100 \%$ at various levels.

Conclusion: This method can be successfully applied for routine quality control analysis of these drugs in bulk and pharmaceutical formulations.

Key Words: Paracetamol, Ibuprofen, RP-HPLC, Quality-by-Design, Degradation, Validation

\section{INTRODUCTION}

Paracetamol (PARA), chemically known as $N$-(4-hydroxyphenyl) acetamide (Figure 1A) is the widely employed non-steroidal anti-inflammatory drug (NSAID) that acts by inhibition of cyclooxygenase-1/2 (COX-1/COX-2) enzyme which prevents the metabolism of arachidonic acid to prostaglandins $\mathrm{H}_{2}$ and $\mathrm{E}_{2}$ thereby lower the hypothalamic set-point to reduced fever. ${ }^{1,2}$ Ibuprofen (IBP), an aryl acetic acid derivative that is chemically known as $(R S)$ 2-(4-(2-methylpropyl)phenyl)propanoic acid (Figure 1B) is a well-known NSAID preferably act by the inhibition of COX-2. ${ }^{3,4}$

While looking at some imperative medical databases such as Google Scholar, Pubmed, etc. for quality analysis (estimation) of these two drugs (PARA and IBP) combination through detailed literature survey, it was observed that certain methods like Ultraviolet-Visible (UV-Vis), ${ }^{5-10}$ High-Performance Liquid Chromatography (HPLC), ${ }^{11-17}$ Ultra-High Pressure Liquid Chromatography (UPLC), ${ }^{18}$ and Spectrofluorometric approach ${ }^{19}$ have been reported. Interestingly, it

\section{Corresponding Author:}

Sangameshwar Kanthale, Research Scholar, School of Pharmacy, Swami Ramanand Teertha Marathwada University, Nanded 431606, Maharashtra, India; Email: sangamkanthale@gmail.com

ISSN: 2231-2196 (Print)

Received: 18.08 .2020
ISSN: 0975-5241 (Online)

Revised: 05.10 .2020
Accepted: 07.11 .2020
Published: 07.12 .2020 
was noticed that no article was available in the literature regarding the "chemometric approach (design of experiment)" used for the simultaneous estimation of PARA and IBP using RP-HPLC. As the chemometric methods are well-known to rationally offer the best logical outcomes, hence, this approach needs to be developed.

Developing and optimizing isocratic HPLC methods is a difficult procedure that requires simultaneous determination of several factors, to optimize more than one response at a time and to gain information on the sensitivity of chromatographic factors along with their interaction effects on the separation characteristics. Hence, the chemometric method which includes the robust applications of factorial design and response surface methodology. ${ }^{20,21}$

This research investigation describes the development and validation of a fast, easy, and sturdy RP-HPLC method for the simultaneous estimation of PARA and IBP using chemometric-design of experiment (DOE) approach.

\section{EXPERIMENTAL}

\section{Chemicals}

The working standards of PARA and IBP were received as generous gift samples from Himalaya Meditek Pvt. Ltd., Dehradun, Uttarakhand. Disodium hydrogen phosphate (AR grade) and methanol (HPLC grade) were procured from Loba Chemie Ltd., Mumbai, Maharashtra. Other analytical grade chemicals, reagents, and solvents were obtained from HiMedia Pvt. Ltd., Mumbai, Maharashtra. HPLC grade water was purchased from the ELGA system. Combiflam ${ }^{\circledR}$ tablets, manufactured by Sanofi India Ltd., Gujarat containing PARA I.P. $325 \mathrm{mg}$ and IBU I.P. $400 \mathrm{mg}$ were acquired from a local pharmacy shop.

\section{Instrumentation}

A JASCO (Japan) HPLC system, equipped with PU 2080 Plus solvent delivery system (pump), MD 2010 plus PDA (detector), and Rheodyne injector with $20 \mu \mathrm{L}$ loop volume was employed. The data were obtained and processed by utilizing the Borwin software v.1.5.

\section{Chromatographic conditions}

The chromatographic separation was achieved utilizing the Thermo ${ }^{\circledR} \mathrm{C}_{18}$ column $(150 \mathrm{~mm} \times 4.6 \mathrm{~mm}$, i.d., $5 \mu \mathrm{m})$. The composition of the mobile phase consisted of methanol and sodium dihydrogen phosphate buffer $(88.3: 11.7 \% \mathrm{v} / \mathrm{v} ; \mathrm{pH}$ 2.5 adjusted with $10 \%$ orthophosphoric acid), delivered at a flow rate of $1.2 \mathrm{~mL} / \mathrm{min}$. The column effluents were monitored at $222 \mathrm{~nm}$.

\section{Preparation of phosphate buffer solution}

The phosphate buffer solution was prepared by dissolving 90 $\mathrm{mg}$ of disodium hydrogen phosphate in $100 \mathrm{~mL}$ of distilled water to produce $10 \mu \mathrm{M}$ concentration. The $\mathrm{pH}$ was adjusted to 2.5 with $10 \%$ orthophosphoric acid.

\section{Preparation of standard stock solution}

The stock solution of PARA and IBP were prepared by dissolving accurately weighed $10 \mathrm{mg}$ of standard drug in $10 \mathrm{~mL}$ of methanol, separately to produce $1000 \mu \mathrm{g} / \mathrm{mL}$ concentration each. Further, $1 \mathrm{~mL}$ of this solution was diluted to $10 \mathrm{~mL}$ to produce $100 \mu \mathrm{g} / \mathrm{mL}$ concentration each.

\section{Preparation of working stock solution}

The working solutions were prepared from the standard stock solution $(100 \mu \mathrm{g} / \mathrm{mL})$ by appropriate dilution in the mobile phase to obtain the final concentration of $6.5-39 \mu \mathrm{g} / \mathrm{mL}$ for PARA and $8-48 \mu \mathrm{g} / \mathrm{mL}$ for IBP, respectively.

\section{Optimization}

The optimization of the mobile phase conditions was performed as per the experimental design by employing a three factor-two level $\left(3^{2}\right)$ response surface method of Central Composite Design (CCD) using the Design-Expert software v.9.0.6 (Stat-Ease Inc., Minneapolis, USA). Methanol volume (A), flow rate (B), and $\mathrm{pH}(\mathrm{C})$ were selected as the independent variables, while the retention time of IBP (tR2) and resolution (Rs2) were taken as responses. The response surface analyses were performed to recognize the effect of different independent variables on the observed responses (Table 1). A total of 20 runs were generated by the DesignExpert software and all the experiments were carried out in a randomized order to reduce the responses of uncontrolled variables that may bring in unfairness on the measurements. The responses were thoroughly evaluated statistically employing the ANOVA process and were observed to be statistically significant. Additionally, the most favourable state was chosen through the numerical optimization procedure employing the desirability function. As the $P$-value was found to be $<0.05$, the quadratic model was used. The quadratic mathematical model for independent factors is depicted by the equation below:

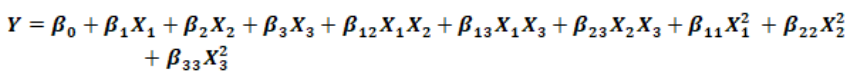

\section{Global Optimization}

In the present study, to optimize the two responses with different targets, Derringer's desirability function was used. The Derringer's desirability function (D) is defined as the geometric mean, weight, or otherwise, of the individual desirability functions. The expression that defines the Derringer's desirability function is given by the equation below.

$$
D=\left[\begin{array}{lll}
d_{1}^{p 1} X & d_{2}^{p 2} X d_{3}^{p 3} X \ldots X d_{n}^{p n}
\end{array}\right]^{1 / n}
$$

Where, $\mathbf{n}$ - the number of responses and Pn- the weight of the responses 
The weight of the response is the relative importance of each of the individual functions di. The relative importance pi is a comparative scale for weighting each of the resulting di in the overall desirability product and it varies from the least important ( $\mathrm{pi}=0.1)$ to the most important $(\mathrm{pi}=10)$. The desirability function (D) can take values from 0 to 1 . The weights can range from 0.1 to 10 . The weights $<1$ give less significance to the desired objective whereas the weights $>1$ described better significance to the desired objective. In the current research, pi values were set at 1 for all the three responses. A value of D close to 1 indicates that the combination of the different criteria is matched in a global optimum. The percentage of prediction error was calculated by the equation below.

$$
\text { Prediction Error }=\frac{\text { Experimental value }- \text { Predicted value }}{\text { Predicted value }} \times 100
$$

\section{Method Validation}

The developed RP-HPLC method was properly corroborated in agreement with the Q2A and Q2B guidelines of the International Council for Harmonization of Technical Requirements for Pharmaceuticals for Human Use (ICH), in assent with the United States Pharmacopoeia (USP), and with the guidance of the United States Food and Drugs Administration (USFDA).

\section{Specificity}

The degree of specificity was determined by injecting the blank solution and placebo (synthetic mixture) solution, and further comparing the peaks in the sample solution. ${ }^{22}$

\section{Linearity}

For the evaluation of the system linearity, five concentrations $(80 \%, 90 \%, 100 \%, 110 \%$, and $120 \%)$ of the target analytical concentration were taken. The solutions were carefully prepared in the presence of a diluent and the equivalent volumes were injected under the particular chromatographic condition. The linearity equation was derived based on the average areas versus the concentration volume and the regression coefficient value $\left(\mathrm{r}^{2}\right)$ was reported. ${ }^{23}$

\section{Accuracy}

The accuracy (recovery) of this RP-HPLC method was estimated by spiking the standard drug in the concentrations of $50 \%, 100 \%$, and $150 \%$ of the target concentration (standard addition method). The process was accomplished in a triplicate way and the acquired mean data were articulated in the form of $\%$ recovery \pm confidence interval with calculated $\%$ relative error, based on the specific concentrations. ${ }^{24}$

\section{Precision}

The precision (variability) of this RP-HPLC method was determined by spiking the standard drug in the concentrations of $80 \%, 100 \%$, and $120 \%$ of the target concentration (standard addition method), three-times in a single day (intra-day variability) and three-times on three different days (inter-day variability). The level of precision was determined through the acquired relative standard deviation (RSD) data. ${ }^{25}$

\section{Robustness}

The deliberate alteration in the systems suitability parameters like mobile phase composition by $\pm 2 \% \mathrm{v} / \mathrm{v}$ (i.e., $90.3: 9.7$ $\% \mathrm{v} / \mathrm{v}$ and $86.3: 13.7 \% \mathrm{v} / \mathrm{v}$ ) and detection wavelength by $\pm 2^{\circ} \mathrm{C}$ (i.e., $224 \mathrm{~nm}$ and $220 \mathrm{~nm}$ ) were methodically studied keeping other factors constant. ${ }^{26}$

\section{System suitability}

The reproducibility characteristics of the system were estimated by spiking the standard solution five-times and determining the parameters like tailing factor (TF), retention time (Rt), theoretical plates (TP), and peak area. ${ }^{27}$

\section{Limit of detection (LOD)}

Limit of detection (LOD) may be defined as the lowest concentration that can be detected by the method but not always necessary to quantify in the exact value. The LOD was determined by the following formula: ${ }^{28}$

$$
\text { LOD }=3.3(\sigma / S)
$$

where $\sigma=$ standard deviation of response and $S=$ slope of the calibration curve. The slope $S$ may be estimated from the calibration curve of the analyte.

\section{Limit of quantification (LOQ)}

Limit of quantification (LOQ) may be defined as the lowest concentration that can be quantified dependably with a particular level of accuracy and precision. The LOQ is determined by the following formula: ${ }^{29}$

$$
\operatorname{LOQ}=10(\sigma / S)
$$

where $\sigma=$ standard deviation of response and $S=$ slope of the calibration curve. The slope $S$ may be estimated from the calibration curve of the analyte.

Assay of Combiflam ${ }^{\circledR}$ Tablets

20 tablets of Combiflam ${ }^{\circledR}$ were accurately weighed and finely powdered. The powder equivalent to $10 \mathrm{mg}$ of PARA and $12.30 \mathrm{mg}$ of IBP was taken and transferred to a $10 \mathrm{~mL}$ volumetric flask. The content was diluted to $10 \mathrm{~mL}$ with methanol and the solution was sonicated for $10 \mathrm{~min}$. The solution was then filtered through Whatman filter paper no. $41.1 \mathrm{~mL}$ of the filtrate solution was diluted to $10 \mathrm{~mL}$ with the mobile phase. Further $1.3 \mathrm{~mL}$ of this solution was diluted to $10 \mathrm{~mL}$ with methanol to achieve a final concentration of $13 \mu \mathrm{g} / \mathrm{mL}$ and $16 \mu \mathrm{g} / \mathrm{mL}$, respectively of PARA and IBP. This procedure was repeated 6 times for the tablet formulation. 


\section{Forced degradation studies}

\section{Alkali degradation studies}

$0.5 \mathrm{mg}$ equivalent of the drug was taken in a $100 \mathrm{~mL}$ volumetric flask and diluent (methanol) was added to exactly the half, sonication was done for 15 min duration, and further, the volume was made up to $100 \mathrm{~mL}$. The content was stirred using the magnetic stirrer for 30 min duration and then at $3,000 \mathrm{rpm}$ centrifugation was done for $5 \mathrm{~min}$. $5 \mathrm{~mL}$ of the above content was taken in a volumetric flask, $10 \mathrm{~mL}$ of 0.1 $\mathrm{N} \mathrm{NaOH}$ solution was added, and the above content was heated at $80^{\circ} \mathrm{C}$ temperature for the duration of $8 \mathrm{hrs}$ under dark condition. The content was neutralized with the same quantity of $\mathrm{HCl}$ and the volume was made up to $100 \mathrm{~mL}$ with the mobile phase. The final content was filtered employing the $0.45 \mu \mathrm{m}$ pore size nylon membrane. ${ }^{30}$

\section{Acid degradation studies}

$0.5 \mathrm{mg}$ equivalent of the drug was taken in a $100 \mathrm{~mL}$ volumetric flask and diluent (methanol) was added to exactly the half, sonication was done for $15 \mathrm{~min}$ duration, and further, the volume was made up to $100 \mathrm{~mL}$. The content was stirred using the magnetic stirrer for 30 min duration and then at 3,000 rpm centrifugation was done for $5 \mathrm{~min}$. $5 \mathrm{~mL}$ of the above content was taken in a volumetric flask, $10 \mathrm{~mL}$ of 0.1 $\mathrm{N} \mathrm{HCl}$ solution was added, and the above content was heated at $80^{\circ} \mathrm{C}$ temperature for the duration of $8 \mathrm{hrs}$ under dark condition. The content was neutralized with the same quantity of $\mathrm{NaOH}$ and the volume was made up to $100 \mathrm{~mL}$ with the mobile phase. The final content was filtered employing the $0.45 \mu \mathrm{m}$ pore size nylon membrane. ${ }^{31}$

\section{Oxidation degradation studies}

The oxidative stress (hydrogen peroxide method) tendered to the drug was determined by dissolving $0.5 \mathrm{mg}$ equivalent weight in $10 \mathrm{~mL}$ of $\mathrm{H}_{2} \mathrm{O}_{2}(3 \% \mathrm{v} / \mathrm{v})$ in a volumetric flask and further boiling for the duration of $1 \mathrm{hr}$. The above content was kept at the room temperature to commence the process of degradation. Then, the content was suitably diluted, further sonicated, and the volume was carefully made up to 100 $\mathrm{mL}$ volume. The final content was filtered employing the $0.45 \mu \mathrm{m}$ pore size nylon membrane. ${ }^{32}$

\section{Photostability studies}

In photostability studies, the compound absorbs the photon and leads to the overlapping of the absorption band which results in valence electron reaching the excited state. $0.5 \mathrm{mg}$ equivalent of the drug was taken in a petri dish and exposed to sunlight for the duration of $12 \mathrm{hrs}$ for a single day. The exposed content was further transferred in a $100 \mathrm{~mL}$ volumetric flask, the mobile phase was added, sonication was performed for $15 \mathrm{~min}$, and the volume was made up to $100 \mathrm{~mL}$. The final content was filtered employing the $0.45 \mu \mathrm{m}$ pore size nylon membrane. The radiations of $254 \mathrm{~nm}$ wavelength com- menced the degradation process and the primary degradation products were determined by RP-HPLC. ${ }^{33}$

\section{Thermal studies}

In the thermolytic study, the drugs instigate degradation via assorted mechanisms under elevated temperatures $\left(>70^{\circ} \mathrm{C}\right)$ in the solution states. The study was performed by taking 0.5 mg content equivalent to the drug, exposed to heat at $80 \pm 1^{\circ} \mathrm{C}$ for $1 \mathrm{hr}$, and evaluated for stability under the stress environment. $10 \mathrm{~mL}$ of methanol was added, sonicated for $15 \mathrm{~min}$, and volume was made up to $100 \mathrm{~mL}$ with the mobile phase. The sample solution was then stirred for $30 \mathrm{~min}$ employing the magnetic stirrer, and filtered through a $0.45 \mu \mathrm{m}$ pore size nylon membrane. $20 \mu \mathrm{L}$ of drug solution was injected into HPLC. ${ }^{34}$

\section{RESULTS AND DISCUSSION}

\section{Optimization}

DoE is an approach that enables researchers to assess the consequences of potential interactions of several variables on productivity concurrently using a restricted number of experiments. From the data generated in preliminary studies while developing the separation for PARA and IBU, limits for experimental levels were eventually recognized.

The statistical parameters obtained from ANOVA for the reduced model are given in Table 2. To get a more realistic model, unimportant terms with corresponding $\mathrm{p}$-value $>0.05$ were removed during the backward elimination process. The adjusted $\mathrm{R}^{2}$ values were well within the satisfactory limits of $\mathrm{R}^{2}>0.80$, publicized that the experimental data are in good fit with the second-order polynomial equations. Since $P$-value is $<0.05$, reveals that all the reduced models are significant. In this study, the signal (response) to noise (deviation) ratio was found to be in the range of 9.04-17.44 (ratio greater than 4 is desirable), suggestive of an adequate signal to noise ratio and therefore the model is significant for the separation process. The $\% \mathrm{CV}$ (coefficient of variation) of all the models were found to less than $10 \%$ revealed that all the models were reproducible, (model can be considered reasonably reproducible if \% CV is less than $10 \%$ ).

As can be seen from the regression equation (Table 2), the positive interaction of factors $\mathrm{A}, \mathrm{B}$, and $\mathrm{C}$ are statistically important for $\mathrm{tR}_{2}$ and $\mathrm{Rs}_{2}$. Altering the factor $\mathrm{A}$ and $\mathrm{B}$, low to high level strongly effect (decreasing order) the $\mathrm{tR}_{2}$ and $\mathrm{Rs}_{2}$. Then altering factor $\mathrm{C}$ show a slight influence $\mathrm{tR}_{2}$ and $\mathrm{Rs}_{2}$ (lower level $\mathrm{C}$ and $\mathrm{A}$ show highest resolution). Therefore, this study discloses that intensifying factors $\mathrm{A}, \mathrm{B}$, and $\mathrm{C}$ will reduce $\mathrm{tR}_{2}$ and $\mathrm{Rs}_{2}$. Hence, a high level of factors $A, B$, and $\mathrm{C}$ will give a shorter run time.

Perturbation plots and 3D response surface plots are depicted 
for the predicted models, to give an improved understanding of the investigated method. This type of plot represents the effect of an independent factor on a specific response with all other factors assumed constant at a reference point. A steepest slope or curvature represents the sensitiveness of the response to specific factors. Figure $\mathbf{2}$ displays the percentage of methanol in the mobile phase (A) is the most important effect on $t R_{2}$ and $R_{2}$ followed by factor $B$ for $t R_{2}$ and factor $\mathrm{C}$ for $\mathrm{Rs}_{2}$. The factor $\mathrm{A}$ and $\mathrm{B}$ are important for decreasing the $\mathrm{tR}_{2}$ and $\mathrm{Rs}_{2}$ but factor $\mathrm{C}$ is also having a little effect on $\mathrm{Rs}_{2}$. So these three factors (A, B, and C) were important for the shorter run time.

The criteria for the optimization of each response are shown in Table 3. As can be seen under the criteria for optimization, the responses $t R_{2}$ and $R_{2}$ were minimized and targeted to shorten the analysis time and give better resolution respectively. Following the conditions and restrictions above, the optimization procedure was carried out. The response surface attained for the global desirability function is presented in Figure 3. It can be concluded that there was a set of coordinates producing high desirability value $(D=0.862)$ were methanol concentration (A) of $88.30 \%, \mathrm{pH} 2.5$ and flow rate of $1.20 \mathrm{~mL} / \mathrm{min}$. The prediction competence of the model was substantiated by executing the experiment under the most favourable state and the respective chromatogram. To attain the obviousness of the suggested model, the assertion between the experimental responses and predicted responses for the envisaged criteria is shown in Table 4.

\section{Chromatographic condition}

The chromatographic separation was achieved using Ther$\mathrm{mo}^{\circledR} \mathrm{C}_{18}$ column $(150 \mathrm{~mm} \times 4.6 \mathrm{~mm}$, i.d., $5 \mu \mathrm{m})$. The optimum composition of the mobile phase consisted of methanol and sodium dihydrogen phosphate buffer $(88.3: 11.7 \% \mathrm{v} / \mathrm{v}$; $\mathrm{pH} 2.5$ adjusted with $10 \%$ orthophosphoric acid) at a flow rate of $1.2 \mathrm{~mL} / \mathrm{min}$, which resolved the degraded peak from the standard peak with Rt values of $2.241 \mathrm{~min}$ for PARA and $3.535 \mathrm{~min}$ for IBU (Figure 4). The UV spectra showed that the drug absorbed appreciably at $222 \mathrm{~nm}$, and therefore, this wavelength was selected as the detection wavelength. The developed method was also found to be specific, since, it was able to separate other excipients present in the dosage form of the drug.

\section{METHOD VALIDATION}

\section{Specificity}

The specificity of this method was estimated where no interference was observed. The observed peaks in the sample solution were the actual peak of PARA and IBP which showed that the method was specific.

\section{Linearity and range}

Over the desired range of $80 \%$ to $120 \%$ of the target analytical concentration, an excellent level of linearity was observed for both the drugs. The linear regression equation for PARA was observed to be $y=52185 x-40419$ with a regression coefficient value $\left(\mathrm{r}^{2}\right)$ of 0.996 and the linear regression equation for PARA was perceived to be $y=120898 \mathrm{x}$ +727251 with a regression coefficient value $\left(\mathrm{r}^{2}\right)$ of 0.995 , which signifies a highly acceptable degree of linearity.

\section{Accuracy}

The accuracy characteristics of the developed method were computed based on the recovery data by employing the calibration curve where the Y-intercept and the slope play a critical role in estimating the \% recovery. The result of the recovery study for PARA was observed to be $101.11 \% \mathrm{w} / \mathrm{w}$ (at $50 \%$ concentration), $99.81 \%$ (at $100 \%$ concentration), and $101.93 \%$ (at $150 \%$ concentration). The $\%$ RSD values were observed to be $1.05 \%, 1.82 \%$, and $0.95 \%$, respectively at three different concentrations; $50 \%, 100 \%$, and $150 \%$ of the target concentration. The result of the recovery study for IBU was observed to be $99.81 \% \mathrm{w} / \mathrm{w}$ (at $50 \%$ concentration), $101.66 \%$ (at $100 \%$ concentration), and $101.23 \%$ (at $150 \%$ concentration). The $\%$ RSD values were observed to be $0.78 \%, 1.30 \%$, and $1.37 \%$, respectively at three different concentrations; $50 \%, 100 \%$, and $150 \%$ of the target concentration. The \% RSD values were found to be within the pharmacopoeia acceptance limit of $\pm 2 \%$ which indicated good accuracy of the developed analytical method.

\section{Precision}

Over the $50 \%, 75 \%$, and $100 \%$ of the target concentration, the $\%$ RSD values were observed to be $1.37 \%, 0.98 \%$, and $1.54 \%$ for PARA and $1.21 \%, 1.40 \%$, and $0.95 \%$ for IBU, respectively under intra-day variability whereas $1.48 \%$, $1.05 \%$, and $1.16 \%$ for PARA and $0.84 \%, 1.72 \%$, and $1.92 \%$ for IBU, respectively under inter-day variability which represents that the developed chromatographic method has high precision value with reduced variability in the estimation of PARA and IBU. The \% RSD values were found to be within the pharmacopoeia acceptance limit of $\pm 2 \%$.

\section{Robustness}

After intentional alterations in the chromatographic conditions such as mobile phase composition by $\pm 2 \%$ v $/ v$ (i.e., 90.3:9.7 \% v/v and 86.3:13.7 \% v/v) and detection wavelength by $\pm 2^{\circ} \mathrm{C}$ (i.e., $224 \mathrm{~nm}$ and $220 \mathrm{~nm}$ ), minute changes in the retention time $( \pm 0.2)$ were observed. The $\%$ RSD values were observed to be within the pharmacopoeia acceptance limit of $\pm 2 \%$ which concluded that the method is robust enough to detect PARA and IBU even after modifications in the chromatographic environment. 


\section{Systems suitability parameters}

The system suitability parameters revealed that the developed analytical method has reproducible attributes, capability for routine analysis, and competent enough to be applied. The average retention time (Rt) of PARA was noticed at $2.227 \mathrm{~min}$ and IBU was perceived at $3.533 \mathrm{~min}$ (Table 5). The number of theoretical plates was recognized to be 2303.029 for PARA and 2278.903 for IBU which are above the prescribed USP limit of 2,000 that may be translated into higher column efficacy, better resolution, and superior separation of the method. The high value of peak area may be correlated with the theoretical separation ability of the developed method. The tailing factor was perceived to be 1.62 for PARA and 1.41 for IBU which represented a good symmetry where the degree of asymmetric factor is also equal to 1 , an ideal form of Gaussian peak where both are factors hold equal magnitude. The method has been found to fulfil the minimum requirements as prescribed in the monographs of USP and has perspectives to express reproducible results.

\section{Forced degradation studies}

After alkaline treatment, PARA and IBU showed no peak of degradation product (Figure 5A). The percent recovery of PARA and IBU was $86.45 \%$ and $91.57 \%$, respectively. After acid hydrolysis, PARA showed one peak of degraded product at Rt value of 2.824 min with $65.81 \%$ recovery. On the other hand, IBU was $80.42 \%$ recovered, with no peak of degradant (Figure 5B). In the oxidative condition, the percent recovery obtained for PARA was $70.46 \%$ and IBU was $96.64 \%$, with no peak of degradant (Figure 5C). In the dry heat degradation condition, the percent recovery obtained for PARA was $95.83 \%$ and IBU was $92.10 \%$, with no peak of degradant (Figure 5D). After the photo-degradation study for UV light and Fluorescence light, PARA was $98.80 \%$ and IBU was $98.58 \%$ recovered, with no peak of degradant (Figure 5E).

\section{Analysis of Marketed Formulation}

The method was successfully used for the determination of PARA and IBU in pharmaceutical formulation Combiflam $^{\circledR}$. The assay results for these NSAID tablets using the proposed method showed a recovery of $100.69 \%$ for PARA and $100.82 \%$ for IBU which indicated the suitability of the method to determine both the contents in the tablet formulations, without detecting the excipients (Table 6). It can be concluded that the method separates the drug from their degradation products and it may be employed for the routine analysis of PARA and IBU in tablets.

\section{CONCLUSION}

This methodology represents a well-organized and easy complete approach to conclude the problem of probing op- timum RP-HPLC conditions. This investigation also proved that the chromatographic techniques coupled with chemometric tools, afford useful information regarding separation and elution time and hence make this combined technique a powerful analytical tool. The validation study also proved that the developed and optimized method was specific, suitable, linear, accurate, precise, and robust for the estimation of PARA and IBP. Therefore, this HPLC method can be used as a routine quality control analysis in a pharmaceutical environment.

\section{ACKNOWLEDGEMENT}

The authors thank Himalaya Meditek Pvt. Ltd., Dehradun, Uttarakhand for providing the gift sample. Thanks are also conveyed to the Director, School of Pharmacy, Swami Ramanand Teertha Marathwada University, Nanded, Maharashtra for his guidance and support.

\section{Conflict of Interest}

There is no conflict of interest regarding the publication of this article.

\section{Funding Information}

No funding was received from any agency.

\section{REFERENCES}

1. Mahapatra DK, Bharti SK. Handbook of Research on Medicinal Chemistry: Innovations and Methodologies. New Jersey: Apple Academic Press, 2017.

2. Mahapatra DK, Bharti SK. Medicinal Chemistry with Pharmaceutical Product Development. New Jersey: Apple Academic Press, 2019.

3. Chhajed SS, Upasani CD, Wadher SJ, Mahapatra DK. Medicinal Chemistry. Nashik: Career Publications Private Limited, 2017.

4. Mahapatra DK, Bharti SK. Drug Design. New Delhi: Tara Publications Private Limited, 2016.

5. Joshi RS, Pawar NS, Katiyar SS, Zope DB, Shinde AT. Development and validation of UV spectrophotometric methods for simultaneous estimation of paracetamol and ibuprofen in pure and tablet dosage form. Der Pharm Sinica. 2011;2(3):164-71.

6. Gondalia R, Mashru R, Savaliya P. Development and validation of spectrophotometric methods for simultaneous estimation of ibuprofen and paracetamol in soft gelatin capsule by simultaneous equation method. Int J ChemTech Res 2010;2(4):1881-5.

7. Chitlange SS, Soni R, Wankhede SB, Kulkarni AA. Spectrophotometric methods for simultaneous estimation of dexibuprofen and paracetamol. Asian J Res Chem 2009;2(1):30-33.

8. Hoang VD, Ly DT, Tho NH, Nguyen MH. UV spectrophotometric simultaneous determination of paracetamol and ibuprofen in combined tablets by derivative and wavelet transforms. Sci World J 2014;1(1):1-13.

9. Mabrouk MM, Moneeb MS, Kamal AH, Wahbi AM. Simultaneous determination of paracetamol and ibuprofen in their tablets by Chemometric spectrophotometry and HPLC. Pak J Pharm Sci 2009;22(1):8-17. 
10. Issa YM, Zayed SM, Habib II. Simultaneous determination of ibuprofen and paracetamol using derivatives of the ratio spectra method. Arab J Chem 2011;4(1):259-63.

11. Balan P, Nimila C, Movva VR, Prasanna ML, Rajasekar S. A validated RP-HPLC method for estimation of dexibuprofen and paracetamol in the combined tablet dosage form. Int $\mathrm{J}$ PharmTech Res 2011;3(3):1293-8.

12. Lakka NS, Goswami N, Balakrishna P. Development and validation of an RP-HPLC for simultaneous determination of ibuprofen and paracetamol in solid dosage forms: Application to dissolution studies. Int J Res Pharm Sci 2011;2(3):331-7.

13. Tsvetkova BG, Pencheva IP, Zlatkov AB, Peikov PT. Development and validation of RP-HPLC method for simultaneous determination of paracetamol and ibuprofen in fixed-dose combinations. Int J Pharm Sci Rev Res 2012;16(1):13-16.

14. Aziz AA, Ahmed K. Simultaneous determination of paracetamol with different active pharmaceutical ingredient (API) and excipient in various dosage forms. Sci Int 2015;27(6):6173-6.

15. Jahan S, Islam J, Begum R, Kayesh R, Rahman A. A study of method development, validation, and forced degradation for simultaneous quantification of paracetamol and ibuprofen in pharmaceutical dosage form by RP-HPLC method. Anal Chem Insights. 2014; 9(1):75-81.

16. Alam I, Khanam N, Ganguly S, Barik S, Siddiqui AR. Development of assay method and forced degradation study of dexibuprofen and paracetamol by RP-HPLC in tablet formulation. Der Pharm Lett. 2014;6(3):184-191.

17. Gnana RM, Geetha G, Sangaranarayanan A. Simultaneous, stability-indicating method development and validation for related compounds of ibuprofen and paracetamol tablets by RP-HPLC method. J Chromat Separation Techniq 2012;3(8):1-5.

18. Makwana S, Patel M, Singh B, Upadhyay J, Shah A. Development and validation of a stability-indicating RP-UPLC method for the determination of paracetamol and ibuprofen in the tablet. J Chem Pharm Res 2015;7(4):1308-15.

19. Luna AS, Pinho JSA. Determination of paracetamol and ibuprofen in tablets and urine using spectrofluorimetric determination coupled with chemometric tools. Austin J Anal Pharm Chem 2014;1(1):1001-1008.

20. Valliappan K, Kannan K, Manavalan R, Muralidharan C. Application of chemometrics in chromatography. Indian J Chem 2002;41(1):7-12.

21. Giriraj P, Kumar S. Development and validation of a rapid - chemometrics assisted RP-HPLC with photodiode array detection method for the simultaneous estimation of dutasteride and tamsulosin hydrochloride in pure and pharmaceutical formulation. Int J Drug Dev Res. 2014;6(2):36-45.

22. Sawale V, Dhabarde DM, Mahapatra DK. Development and validation of UV spectrophotometric method for simultaneous esti- mation of olmesartan medoxomil and chlorthalidone in bulk and pharmaceutical dosage form. Eur J Anal Chem 2017;12(1):5566.

23. Jha SK, Bhaskaran S, Kamble MA, Mahapatra DK. A novel RPHPLC based assay for the estimation of Tramadol $\mathrm{HCl}$ content in tablets: Development and Validation. Inventi Impact Pharm Anal Qual Assur 2017;2017(4):142-6.

24. Puranik M, Shambharkar S, Nimbalkar S, Mahapatra DK. Comparison of UV Spectrophotometric and RP-HPLC Method for the Estimation of Deflazacort in Solid Dosage Form. J Appl Pharm Sci 2020; 10(7):82-8.

25. Murarka BG, Mahapatra DK, Bagde SM, Mahajan UN, Pise AG. Saxagliptin and Metformin Estimation in Tablet Formulation. Int J Pharm Phytopharmacol Res 2020;10(2):27-36.

26. Prakash O, Mahapatra DK, Singh R, Singh N, Verma N, Ved A. Development of a New Isolation Technique and Validated RPHPLC method for Quercetin and Kaempferol from Azadirachta indica leaves. Asian J Pharm Anal 2018;8(3):164-8.

27. Sabale PM, Bhagwat D, Sabale VP, Mahapatra DK. Development and Validation of RP-HPLC method for Simultaneous Estimation of Esomeprazole and Domperidone in Capsule Formulation. Eurasian J Anal Chem 2018;13(6):57-66.

28. Kanthale SB, Thonte SS, Mahapatra DK. Development of Validated Stability Indicating RP-HPLC Method for the Estimation of Glecaprevir and Pibrentasvir in Bulk and Pharmaceutical Dosage Form. J Appl Pharm Sci 2019;9(6):52-60.

29. Kanthale SB, Thonte SS, Mahapatra DK. Stability Indicating RP-HPLC Method for the Simultaneous Estimation of Ivabradin and Metoprolol in Bulk and Tablet Formulation. J Appl Pharm Sci 2019;9(4):137-44.

30. Deodhe ST, Dhabarde DM, Kamble MA, Mahapatra DK. Novel stability indicating RP-HPLC method for the estimation of Pinaverium bromide in tablet formulation: assay development and validation. Eur J Anal Chem 2017;12(2):3-16.

31. Deodhe ST, Dhabarde DM, Kamble MA, Mahapatra DK. Development and validation of a novel stability indicating RP-HPLC method for the estimation of Entecavir in tablet formulation. Eur J Anal Chem 2017;12(3):223-35.

32. Kanthale SB, Thonte SS, Pekamwar SS, Mahapatra DK. Development and Validation of a Stability Indicating RP-HPLC Method for the Determination of Prucalopride succinate in Bulk and Tablet. Int J Pharm Sci Drug Res 2020;12(2):166-74.

33. Sudharshini S, Rathinaraj BS, Kumar P. Quantitative Analysis of Flutamide in Bulk Drug and its Pharmaceutical Dosage Form by using HPLC. Int J Curr Res Rev 2019;11(4):14-19.

34. Kalluru H, Vinodhini C, Satish SK, Surulivel RM, Chitra K, Mangathayaru K. Validated RP-HPLC Method for Quantification of Paclitaxel in Human Plasma-Eliminates Negative Influence of Cremophor El. Int J Curr Res Rev 2018;10(13):5-10.

Table 1: Central composite design (CCD) consisting of experiments for the study of three factors with two responses.

\begin{tabular}{|c|c|c|c|c|c|}
\hline RUN & $\begin{array}{c}\text { FACTOR 1 } \\
\text { (A): METHANOL } \\
\text { (\%) }\end{array}$ & $\begin{array}{c}\text { FACTOR 2 } \\
\text { (B): FLOW RATE } \\
(\mathrm{ml} / \mathrm{min})\end{array}$ & $\begin{array}{c}\text { FACTOR }_{3} \\
\text { (C): } \mathbf{p H}\end{array}$ & $\begin{array}{l}\text { RESPONSE } 1 \\
\text { Retention time } \\
\left(\mathbf{t R}_{2}\right)\end{array}$ & $\begin{array}{c}\text { RESPONSE } 2 \\
\text { Resolution } \\
\left(\text { Rs }_{2}\right)\end{array}$ \\
\hline 1 & 81.60 & 1.00 & 3.00 & 8.640 & 4.220 \\
\hline 2 & 85.00 & 0.80 & 2.50 & 9.603 & $5 \cdot 579$ \\
\hline 3 & 85.00 & 1.20 & 2.50 & 6.183 & 3.109 \\
\hline 4 & 85.00 & 0.80 & 3.50 & 5.660 & 1.222 \\
\hline 5 & 85.00 & 1.20 & 3.50 & 4.927 & 2.335 \\
\hline 6 & 90.oo & 1.00 & 3.00 & 4.220 & 1.240 \\
\hline
\end{tabular}


Table 1: (Continued)

\begin{tabular}{|c|c|c|c|c|c|}
\hline RUN & $\begin{array}{c}\text { FACTOR I } \\
\text { (A): METHANOL } \\
(\%)\end{array}$ & $\begin{array}{c}\text { FACTOR } 2 \\
\text { (B): FLOW RATE } \\
(\mathrm{ml} / \mathrm{min})\end{array}$ & $\begin{array}{c}\text { FACTOR }_{3} \\
\text { (C): pH }\end{array}$ & $\begin{array}{c}\text { RESPONSE } 1 \\
\text { Retention time } \\
\left(\mathbf{t R}_{2}\right)\end{array}$ & $\begin{array}{l}\text { RESPONSE } 2 \\
\text { Resolution } \\
\left(\mathrm{Rs}_{2}\right)\end{array}$ \\
\hline 7 & 90.00 & 1.00 & 3.84 & 4.626 & 1.757 \\
\hline 8 & 90.00 & 1.00 & 3.00 & 4.273 & 1.310 \\
\hline 9 & 90.00 & 1.00 & 3.00 & 4.210 & 1.242 \\
\hline 10 & 90.00 & 1.00 & 3.00 & 4.223 & 1.274 \\
\hline 11 & 90.00 & 1.33 & 3.00 & 3.177 & 1.848 \\
\hline 12 & 90.00 & 1.00 & 3.00 & 4.270 & 1.250 \\
\hline 13 & 90.00 & 1.00 & 3.00 & 4.225 & 1.244 \\
\hline 14 & 90.00 & 0.66 & 3.00 & 6.397 & 1.974 \\
\hline 15 & 90.00 & 1.00 & 2.15 & 4.927 & 1.801 \\
\hline 16 & 95.00 & 0.80 & 3.50 & 4.790 & 0.838 \\
\hline 17 & 95.00 & 1.20 & 2.50 & 3.593 & 1.811 \\
\hline 18 & 95.00 & 1.20 & $3 \cdot 50$ & 3.255 & 0.748 \\
\hline 19 & 95.00 & 0.80 & 2.50 & $5 \cdot 333$ & 1.613 \\
\hline 20 & 98.40 & 1.00 & 3.00 & 3.541 & 0.870 \\
\hline
\end{tabular}

Table 2: Reduced response model and statistical parameters obtained from ANOVA (After backward elimination).

\begin{tabular}{lcc} 
RESPONSE & \multicolumn{1}{c}{$\mathbf{R}_{2}$} & $\mathbf{R s}_{2}$ \\
Regression Equation & $+4.23-1.29 \mathrm{~A}-0.91 \mathrm{~B}-0.45 \mathrm{C}+0.053 \mathrm{AB}+0.48 \mathrm{AC}$ & $+1.17-0.92 \mathrm{~A}-0.13 \mathrm{~B}-0.49 \mathrm{C}+0.14 \mathrm{AB}+0.45 \mathrm{AC}+$ \\
& $+0.31 \mathrm{BC}+0.68 \mathrm{~A}^{2}+0.22 \mathrm{~B}^{2}+0.21 \mathrm{C}^{2}$ & $0.45 \mathrm{BC}+0.54 \mathrm{~A}^{2}+0.24 \mathrm{~B}^{2}+0.20 \mathrm{C}^{2}$ \\
Adjusted R & 0.909 & $<56$ \\
Model p-value & $<0.0001$ & $<.0001$ \\
Adequate Precision & 17.447 & 8.049 \\
$\% \mathrm{CV}$ & 9.73 & 8.46 \\
\hline
\end{tabular}

Table 3: Criteria for optimization of individual responses.

\begin{tabular}{lcccc} 
RESPONSE & LOWER LIMIT & UPPER LIMIT & \multicolumn{2}{c}{ CRITERIA-I } \\
$\mathrm{tR}_{2}$ & & & Goal & Importance \\
$\mathrm{Rs}_{2}$ & 3.177 & 9.180 & Minimize & 3 \\
\hline
\end{tabular}

Table 4: The comparison of observed and predicted values under optimum condition.

\begin{tabular}{lccccc} 
OPTIMUM CONDITIONS & METHANOL (\%) & FLOW RATE $(\mathbf{m L} / \mathbf{m i n})$ & $\mathbf{p H}$ & $\mathbf{t R}_{2}$ & $\mathbf{R s}_{2}$ \\
Predictive & 88.30 & 1.2 & 2.5 & 3.547 & 2.000 \\
Experimental & 88.30 & 1.2 & 2.5 & 3.533 & 2.063 \\
& & & & & \\
Percent Error (\%) & - & - & - & 0.396 & 3.15 \\
\hline
\end{tabular}

Desirability value $(\mathrm{D})=0.862$ 
Table 5: Validation results of developed and optimized reverse phase chromatographic method.

$\begin{array}{llr}\text { PARAMETERS } & \text { PARACETAMOL } & \text { IBUPROFEN } \\ \text { Specificity } & \text { No interference } & \text { No interference }\end{array}$

System suitability
a) RT
b) Theoretical plates
c) Asymmetric factor
d) Resolution

Range

Linearity

\section{Accuracy}

a) $50 \%$

b) $100 \%$

c) $150 \%$

Precision- Intra day

Precision- Inter day

Robustness

a) Wavelength

$+2 \mathrm{~nm}$

$-2 \mathrm{~nm}$

b) Mobile phase

$+2 \%$

$-2 \%$

LOD

LOQ

\begin{tabular}{|c|c|}
\hline \multicolumn{2}{|c|}{$2.227 \mathrm{~min}$} \\
\hline \multicolumn{2}{|c|}{2303.029} \\
\hline \multicolumn{2}{|c|}{1.62} \\
\hline \multicolumn{2}{|c|}{ - } \\
\hline \multicolumn{2}{|c|}{$6.5-39 \mu \mathrm{g} / \mathrm{mL}$} \\
\hline \multicolumn{2}{|c|}{$\begin{aligned} y= & 52185 x-40419 \\
& R^{2}=0.996\end{aligned}$} \\
\hline \% Recovery & \% RSD \\
\hline 101.11 & 1.05 \\
\hline 99.81 & 1.82 \\
\hline 101.93 & 0.95 \\
\hline
\end{tabular}

Concentration
a) 13
b) 19.5
c) 26

Concentration
a) 13
b) 19.5
c) 26

Detection value

224

220

90.57

87.03

2.06

6.26
\% RSD

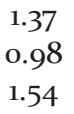

1.54

\% RSD

1.48

1.05

1.16

\% RSD

0.74

1.25

1.83

1.49
No interference

$$
\begin{gathered}
3.533 \mathrm{~min} \\
2278.903 \\
1.41 \\
2.063
\end{gathered}
$$

$8-48 \mu \mathrm{g} / \mathrm{mL}$

$$
\begin{gathered}
y=120898 x+727251 \\
R^{2}=0.995
\end{gathered}
$$

$\begin{array}{cc}\text { \% Recovery } & \text { \% RSD } \\ 99.81 & 0.78 \\ 101.66 & 1.30 \\ 101.23 & 1.37\end{array}$

Concentration $\quad \%$ RSD

$\begin{array}{ll}\text { a) } 16 & 1.21 \\ \text { b) } 24 & 1.40 \\ \text { c) } 32 & 0.95\end{array}$

\begin{tabular}{|c|c|c|c|c|c|c|c|c|}
\hline \multirow[t]{2}{*}{ S. No. } & \multicolumn{4}{|c|}{ PARACETAMOL } & \multicolumn{4}{|c|}{ IBUPROFEN } \\
\hline & $\begin{array}{l}\text { Actual } \\
\text { amount }\end{array}$ & Peak area & $\begin{array}{c}\text { Amount Re- } \\
\text { covered }(\mu \mathrm{g} / \\
\mathrm{mL})\end{array}$ & \% Recovery & $\begin{array}{l}\text { Actual } \\
\text { amount }\end{array}$ & Peak area & $\begin{array}{l}\text { Amount Recov- } \\
\text { ered }(\mu \mathrm{g} / \mathrm{mL})\end{array}$ & \% Recovery \\
\hline 1 & 13 & 654834.9 & $13 \cdot 32$ & 102.48 & 16 & 2697852.0 & 16.29 & 101.87 \\
\hline 2 & 13 & 640342.6 & 13.04 & 100.34 & 16 & 2689896.9 & 16.23 & 101.46 \\
\hline 3 & 13 & 644723.1 & 13.12 & 100.99 & 16 & 2699887.6 & 16.31 & 101.97 \\
\hline 4 & 13 & 640045.8 & 13.03 & 100.30 & 16 & 2699999.0 & 16.31 & 101.98 \\
\hline 5 & 13 & $639987 \cdot 4$ & 13.03 & 100.29 & 16 & 2629896.8 & $15 \cdot 73$ & 98.36 \\
\hline 6 & 13 & 636342.8 & 12.96 & 99.75 & 16 & 2647690.9 & 15.88 & 99.27 \\
\hline Mean & & & & 100.69 & & & & 100.82 \\
\hline $\begin{array}{l}\text { SD } \\
\text { \%RSD }\end{array}$ & \multicolumn{4}{|c|}{$\begin{array}{l}0.959 \\
0.952\end{array}$} & \multicolumn{4}{|c|}{$\begin{array}{l}1.590 \\
1.577\end{array}$} \\
\hline
\end{tabular}

Concentration $\quad \%$ RSD

$\begin{array}{ll}\text { a) } 16 & 0.84 \\ \text { b) } 24 & 1.72 \\ \text { c) } 32 & 1.92\end{array}$

Detection value \% RSD

$\begin{array}{lll}224 & & 1.79 \\ 220 & & 1.56 \\ & & \\ 90.57 & & 1.48 \\ 87.03 & & 1.72 \\ & 1.56 & \\ & 4.75 & \\ & & \\ & \end{array}$

Table 6: Assay result for PARA and IBP in Combiflam tablet by proposed methods. 
<smiles>CC(=O)Nc1ccc(O)cc1</smiles><smiles>CC(C)Cc1ccc(C(C)C(=O)O)cc1</smiles>

Figure 1: Structure of (A) Paracetamol (B) Ibuprofen.

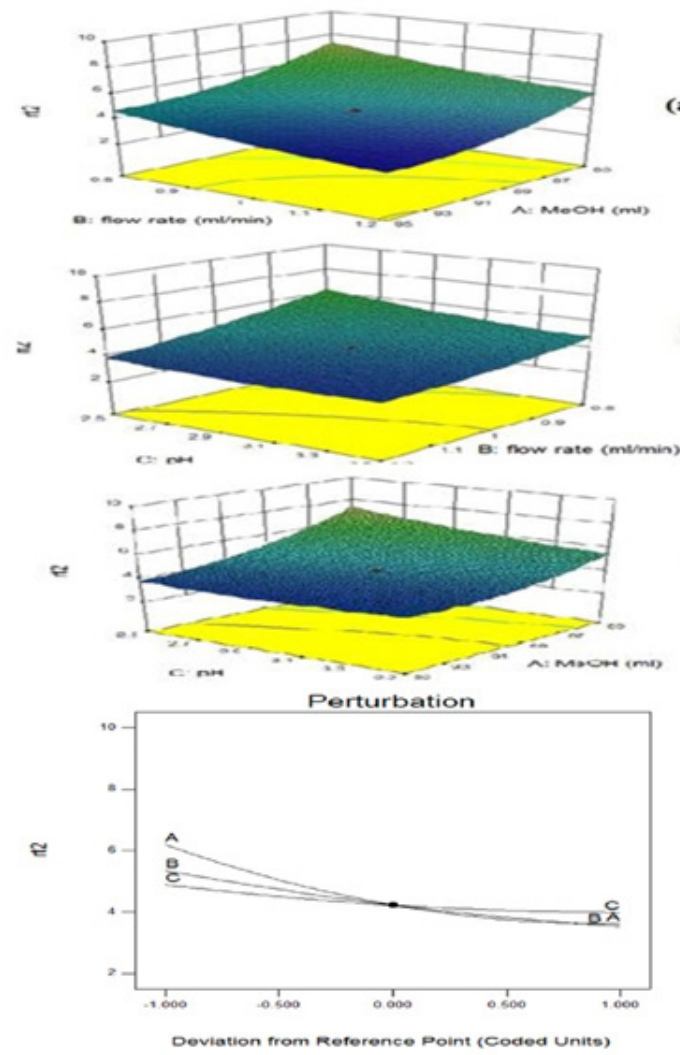

(a) 3

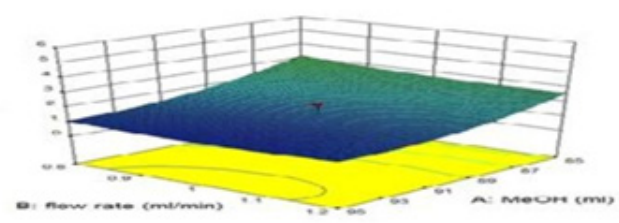

(b) $x$

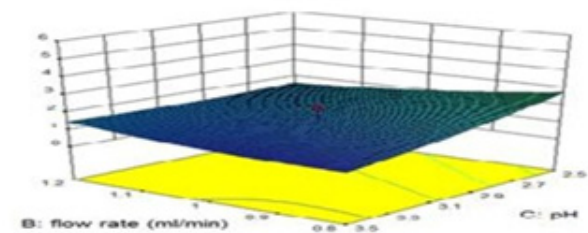

(c)

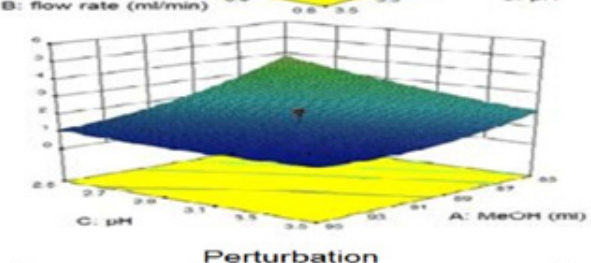

(d)

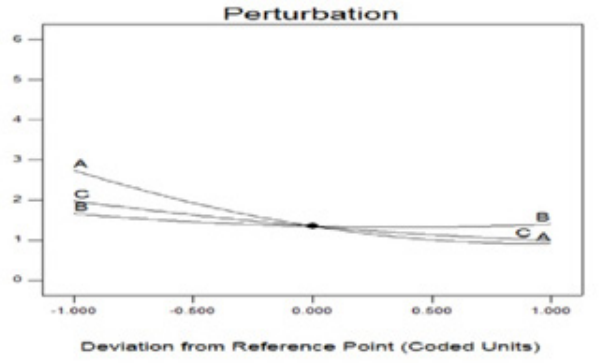

Figure 2: 3D response surface plots: $(\mathrm{A})$ methanol, $(\mathrm{B})$ flow rate, $(\mathrm{C}) \mathrm{pH}$, and (D) perturbation plots.

Desirability

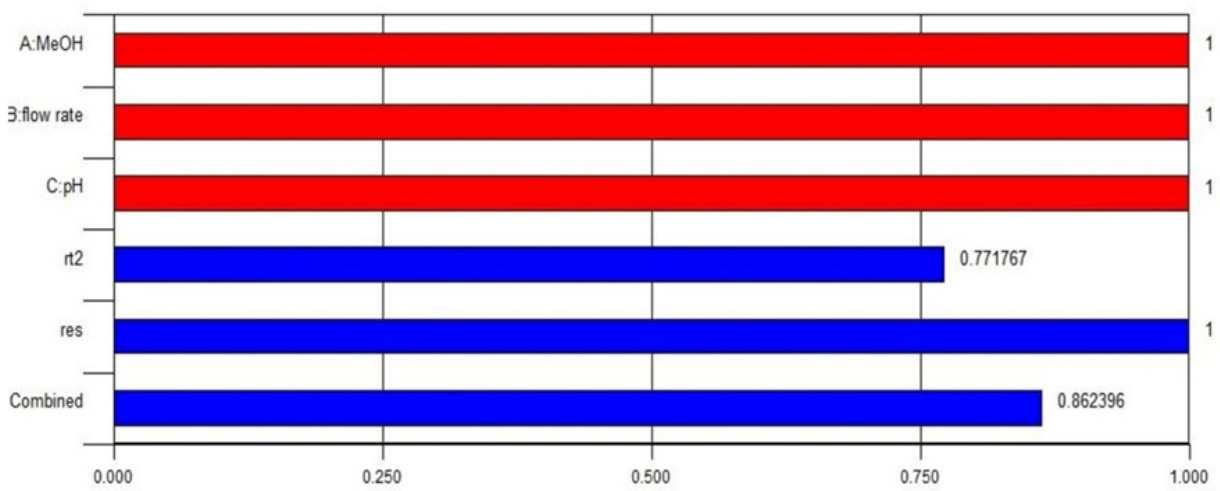

Figure 3: Depiction of global desirability function. 


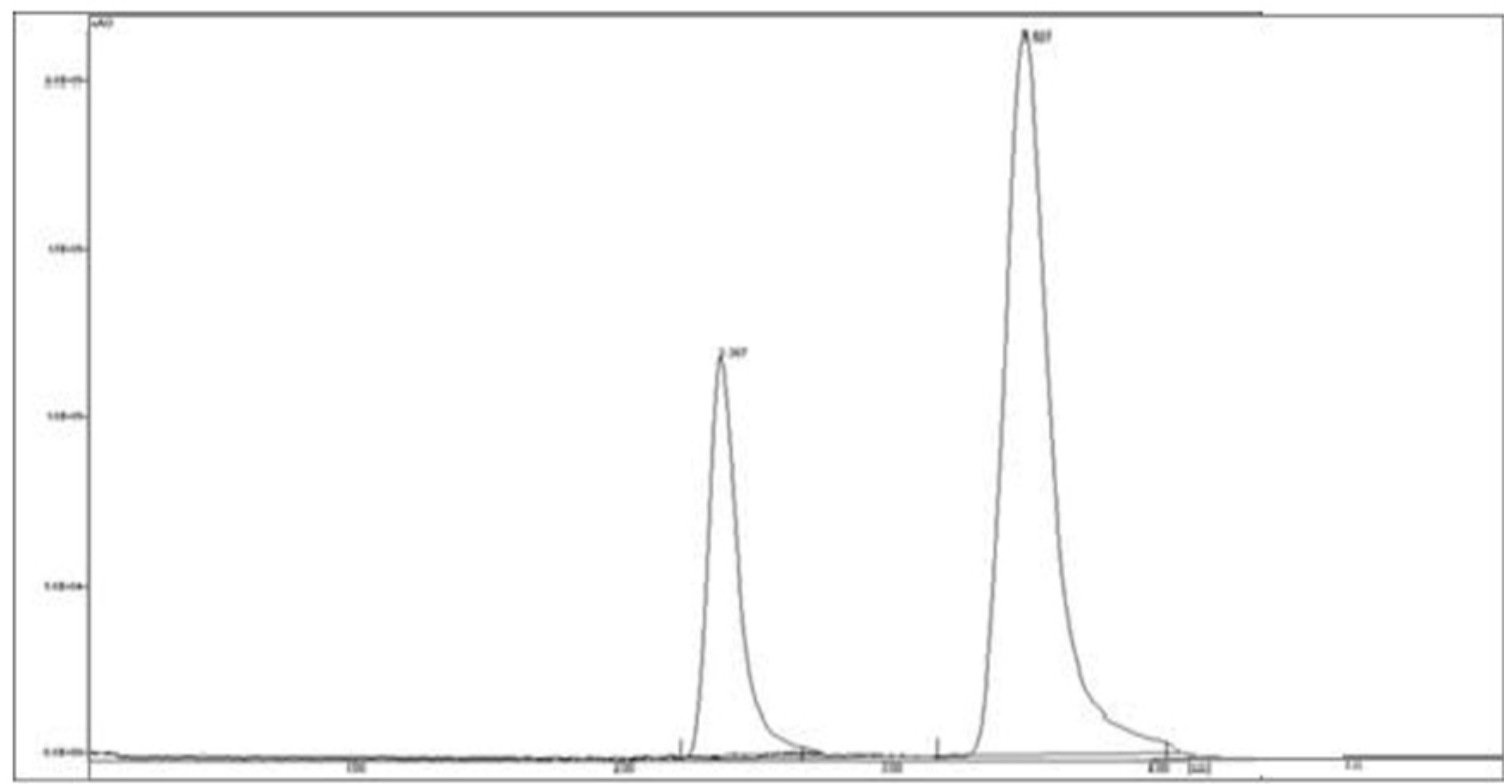

Figure 4: Chromatogram representing the retention time of paracetamol (2.241 $\mathrm{min}$ ) and ibuprofen (3.535 min).

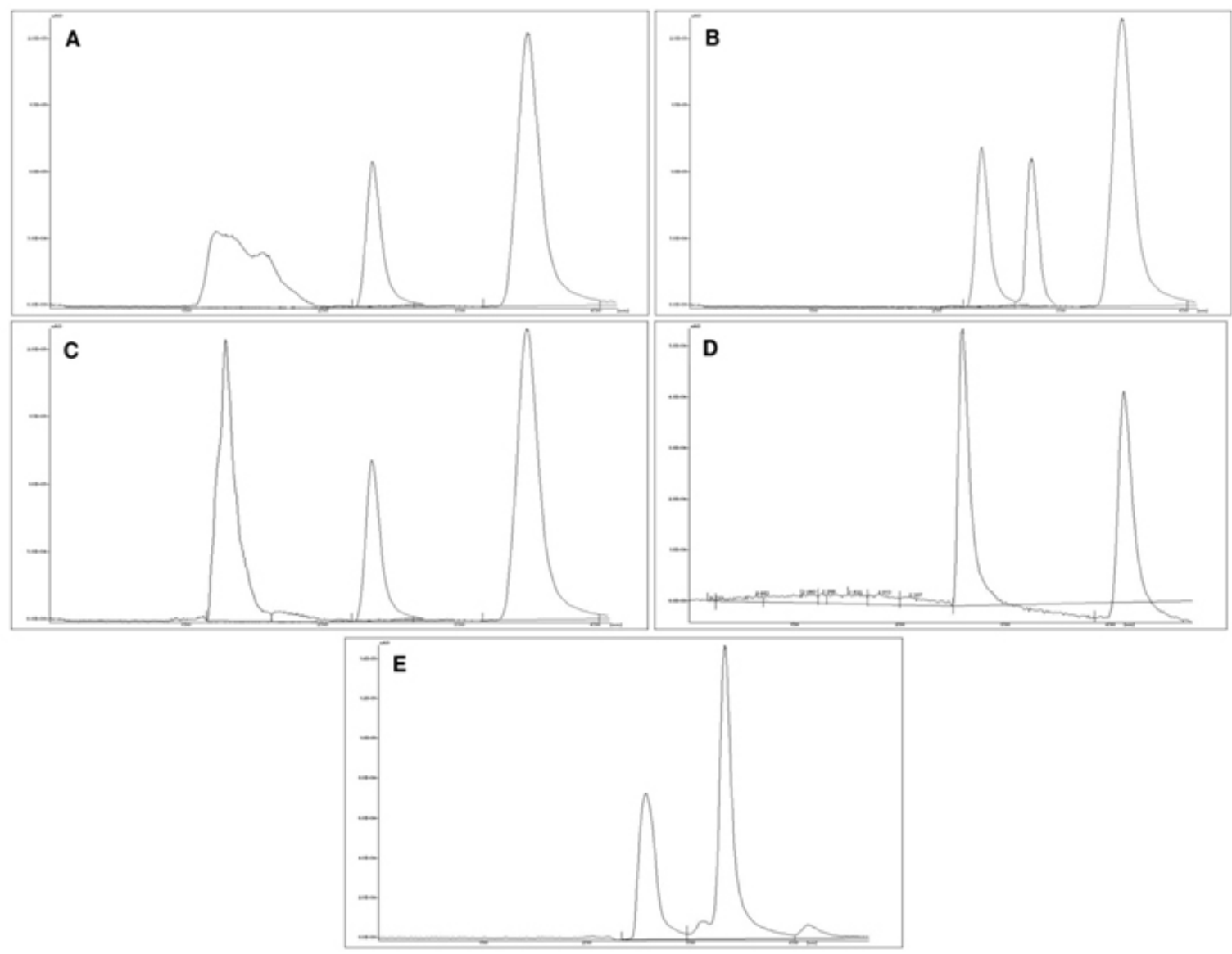

Figure 5: Chromatograms of forced degradation investigation under conditions of: $(A)$ Alkaline treatment, $(B)$ Acid treatment, (C) Oxidative stress, (D) Dry-heat environment, and (E) Photo-degradation. 